\title{
Analisis Penggunaan Similes dan Metaphors pada Novel Berjudul “Hard Time” sebagai Tulisan Deskriptif
}

\author{
Lilik Damayanti ${ }^{1}$, Abdul Gafur ${ }^{2}$, Sunarno $^{3}$ \\ ${ }^{1,2,3}$ Politeknik Negeri Balikpapan, Jl. Soekarno Hatta Km. 8, Balikpapan \\ *lilik.damayanti@poltekba.ac.id
}

\begin{abstract}
Figurative language is a way to engage readers and deliver them through writing in a more creative form. The two categories of figurative languages that are most widely known are similes and metaphors. The purpose of this study was to analyze the use of similes and metaphors contained in a literary work in the form of a novel entitled "hard times". The method used in this study is descriptive qualitative by describing the results of the analysis in the form of data which has taken from one section or chapter found in the novel by Charles Dickens, which consists of 10 pages. The results of this study are the use of similes is more emphasized on the use of "as" than the use of "like". The use of similes "as" and "like" in the novel are used as a form of figurative speech which is made as a comparison between two objects of various types. Using similes in the novel can give a better sense and convey it to the reader. Whereas for metaphors there are only found five sentences because in this writing use more direct speech or direct quotations to emphasize the function of metaphor to live the story in the novel.
\end{abstract}

Keywords: similes, metaphors, descriptive, figurative speech

\begin{abstract}
Abstrak
Bahasa figuratif adalah cara untuk melibatkan pembaca dan mengantarkan mereka melalui tulisan dengan bentuk yang lebih kreatif.Dua kategori bahasa figuratif yang paling dikenal secara luas adalah similes dan metaphors.Tujuan dari penelitian ini adalah untuk menganalisa penggunaan simile dan metafora yang terdapat dalam suatu karya sastra berupa novel berjudul "Hard Times".Metode yang digunakan pada penelitian ini adalah deskriptif kualitatif yaitu dengan memaparkan hasil analisis dalam bentuk data yang diambil dari satu bagian atau chapter yang terdapat pada novel berjudul karya Charles Dickens, yang terdiri dari 10 halaman.Hasil dari penelitian ini yaitu penggunaan similes lebih ditekankan pada penggunaan "as" dibandingkan penggunaan "like".Penggunaan simile "as" dan "like" pada novel tersebut digunakan sebagai bentuk dari figurative speech yang dibuat sebagai perbandingan antara dua objek dari berbagai jenis.Dengan menggunakan similes pada novel tersebut dapat memberikan rasa dengan lebih baik dan menyampaikannya kepada pembaca.Sedangkan untuk metaphors hanya terdapat 5 bentuk kalimat dikarenakan pada penulisan ini banyak menggunakan direct speech atau kutipan langsung untuk menekankan kepada fungsi metafora untuk menghidupkan cerita dalam novel tersebut.
\end{abstract}

Kata kunci: simile, metafora, deskriptif, bahasa figuratif

\section{Pendahuluan}

Karya sastra merupakan buah imajinasi dan kreatifitas pengarang yang disampaikan melalui tulisan.Tulisan-tulisan tersebut disusun berdasarkan kaidah-kaidah kesusastraan yang ada sehingga disusun menjadi suatu bentuk karangan yang baik.Karangan yang baik adalah karangan yang dapat mengungkapkan pikiran dan perasaan pengarang dalam satu kesatuan tema yang utuh, atau rangkaian hasil pemikiran atau ungkapan perasaan ke dalam bentuk tulisan yang teratur. Karangan terdiri dari beberapa paragraf yang masing-masing berisi pikiran-pikiran utama dan kemudian diikuti dengan pikiran penjelas (Widjono, 2007).Maka, karangan merupakan hasil gagasan yang dituangkan dalam bentuk bahasa tulis berupa beberapa kalimat yang membentuk paragraf yang dapat dibaca dan dipahami pembaca.

Beberapa karya sastra tersebut diantaranya adalah novel, novelet, cerpen, cerbung dan roman.Masing-masing karya sastra tersebut memiliki ciri dan kaidah penyusunan 
tersendiri.Namun sering kali dianggap sama karena belum begitu mengerti perbedaannya. Novel sebagai salah satu bentuk karya sastra yang seringkali digunakan seorang penulis sebagai media untuk menyampaikan gagasan atau ide, dimana dalam novel tersebut dapat menggambarkan bagaimana penulis menggunakan alur yang kompleks, latar yang luas, penokohan yang detail, juga waktu yang lama. Salah satu ciri novel yaitu menggunakan bahasa narasi dan deskripsi (Kosasih, 2011).

Teks deskripsi merupakan jenis teks yang banyak digunakan dalam kehidupan seharihari dalam menggambarkan benda, tempat, manusia, hewan dan lain sebagainya. Teks deskripsi diartikan sebagai sebuah teks bahasa Inggris untuk menggambarkan seperti apa benda atau mahluk hidup yang kita deskripsikan, baik secara kenampakan, bau, suara, tekstur, jumlah, maupan sifat-sifatnya dari benda atau makhluk hidup tersebut.Dengan cara ini, penulis dapat terhubung dengan pembaca melalui pengalaman hidup atau pengamatan langsung dari penulis.

Dalam menulis Novel, berbagai macam ragam bahasa dapat digunakan oleh penulis, contohnya dengan menggunakan bahasa yang bermakna harfiah (makna yang sebenarnya) atau makna figuratif (bahasa kiasan). Makna harfiah berarti persis apa yang dikatakannya, sementara makna figuratif menggunakan perumpamaan, metafora, hiperbola, dan personifikasi untuk menggambarkan sesuatu melalui perbandingan dengan sesuatu yang berbeda.

Shawna Malvini (2017), menyebutkan bahwa Metaphora sebagai bahasa figuratif digunakan untuk membandingkan antara satu benda dengan yang lainnya, sinyal (tanda) memiliki makna yang lebih complex dan dapat digunakan sebagai sarana untuk pengumpulan data secara kualitatif dan analisis.Pengungkapan bahasa yang masih mempertahankanunsur kelangsungan makna atau tidak ada usaha untuk menyembunyikan sesuatu di dalamnya, maka bahasa itu merupakan bahasa biasa. Sebaliknya, pengungkapan bahasa yang mengandung perubahan makna seperti makna konotatif (sudah menyimpang jauh dari makna denotatifnya), bahasa itu merupakan bahasa kias atau majas.

Bahasa figuratif adalah cara untuk melibatkan pembaca dan mengantarkan mereka melalui tulisan dengan bentuk yang lebih kreatif.Dua kategori bahasa figuratif yang paling dikenal secara luas adalah similes dan metaphors.Dalam prakteknya, penulis tidak secara eksklusif menggunakan similes dan metaphors, karena terlalu sering menggunakan salah satu bentuk dapat mengganggu pemahaman pembaca.Tujuan dari penggunaan similes dan metaphors adalah untuk memberikan rasa pada suatu tulisan dengan lebih baik dan menyampaikannya kepada pembaca.Dengan menggunakan bahasa kiasan, penulis dapat menciptakan penekanan dan memberikan makna secara simbolik pada suatu karya sastra.

Maka penelitian ini difokuskan pada bagaimana penggunaan bahasa figuratif yang adapada bentuk karangan deskriptif yaitu novel yang berjudul "Hard Time", yang diklasifikasikan menjadi dua bentuk , yaitu: (1) similes yaitu kalimat yang menggunakan katakata seperti "like" atau "as"; (2) metaphors yaitu kalimat yang secara langsung menyatakan perbandingan atau perumpamaan.

\section{Metodologi}

Penelitian ini menggunakan pendekatan deskriptif dan memaparkan data berupa klausa ataupun kalimat.Penelitian ini dilakukan dengan metode kualitatif karena berfokus pada analisis makna, konsep, definisi, dan deskripsi dari suatu novel yang berjudul "hard time".

Sumber data yang digunakan dalam penelitian ini didasarkan pada novel yang berjudul "Hard Time".Pemilihan novel ini didasarkan pada popularitas novel ini sendiri di era 80an, dan juga karena novel ini dijadikan salah satu sumber bacaan yang berbentuk deskriptif, sehingga penulis merasa perlu untuk meneliti bentuk figuratif speech yang ada dalam novel ini untuk dapat dijadikan acuan atau sumber bahan ajar bagi mahasiswa dalam mempelajari dan membuat karangan deskriptif. Sumber data ini juga diperkuat oleh data yang diambil dari 
artikel dan buku dari banyak sumber yang menjelaskan secara mendalam tentang karangan deskriptif umumnya dan figuratif speechkhususnya. Semua definisi dan makna ditemukan dari sumber terpercaya, seperti buku dan artikel dari internet.

Data memiliki peran yang sangat penting dalam penelitian, karena tanpa data tidak mungkin untuk mendapatkan hasil penelitian. Untuk mendapatkan data, penelitian harus menggunakan instrumen pengumpulan data, yaitu: (1) Observasi; (2) Wawancara, dan (3) Dokumen.

Dalam penelitian ini menggunakan dokumen sebagai instrumen pengumpulan data.Dokumen adalah jenis sumber data yang melibatkan kutipan apapun yang bertujuan untuk menguji penelitian, seperti sebuah artikel, buku, dll.

Data akan dianalisis setelah proses pengumpulan data. Analisis akan difokuskan pada penggunaan bahasa figuratif yaitu, similes, dan metaphors.Dalam proses analisa, data akan dianalisis melalui langkah-langkah berikut: (1) mengidentifikasi bentuk figuratif speech, (2) klasifikasi similies dan metaphors, (3) menganalisis pengaruh penggunaan similes dan metaphors.

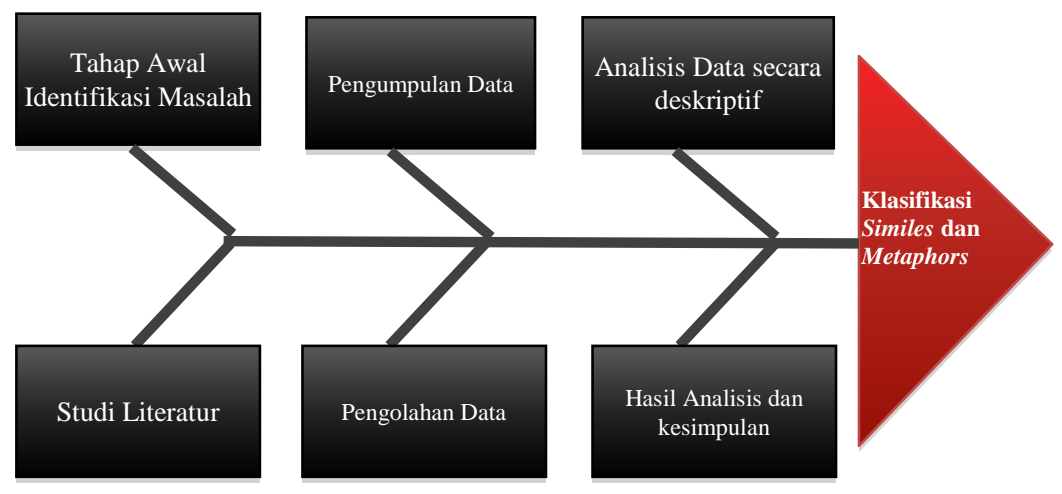

Gambar 1. Diagram Alir Penelitian

\section{Hasil dan Pembahasan}

Pada bagian ini akan dipaparkan beberapa data yang telah diambil dari sebuah novel berjudul "Hard Time" oleh Charles Dickens. Dari Novel tersebut akandianalisis dan diklasifikasi penggunaan similes dan metaphorssebagai bagian dari figurative speech dan sering digunakan sebagai bagian dari karangan berbentuk deskriptif.

Similes adalah salah satu bentuk dari figurative speech yang menggunakan kata-kata "like" dan "as" dalam menuliskan kalimatnya atau teks sehingga menjadi suatu bentuk kalimat perumpamaan yang membandingkan dua hal (Alm-Arvius, 2003)dalam kalimat yang mengandung simile, kita membuat perbandingan antara dua objek dari berbagai jenis.Kedua benda ini setidaknya memiliki satu titik kesamaan.

\subsection{Penggunaan Similes “as”}

- He went down to the Bank himself as soon as it was opened.... (hal597, baris ke-25)

- She gave her hand to Sissy, as if she meant with her help too. (hal 597, baris ke-61)

- It was the more hopeful, as the town to which Sissy had directed....(hal 598, baris ke-33)

- Master, Kidderminster, grown too maturely turfy to be received by the wildest credulity as Cupid anymore,.... (hal 598, baris ke-113)

- The emperor of Japan, on a steady old white horse stenciled with black spots, was twirling five wash-hand basins at once, as it is favorite recreation of that monarch to do. (hal 598, baris ke-127)

- ... on which the box company stamped their approbation as if the were coming through. (hal 599, baris ke-38) 
- They saw Mr. Sleary bring out a chair and sit down by the side door, smoking; as if that were his signal that they might approach.(hal 600, baris ke-44)

- "Your thervant, Thquire, "was his cautious salutation as they passed in..(hal 600, baris ke-48)

- ...until he stood in the sawdust, on the verge of the circle, as far as possible, within its limits from where his father sat..(hal 600, baris ke-80)

- "Give me your hand, my poor boy, and may God forgive you as I do!'..(hal 601, baris ke30)

- .... his colorless face more colorless than ever, as if he ran himself into a white heat....(hal 601, baris ke-63)

- There he stood, panting and heaving, as if he had never stopped since the night,....(hal 601, baris ke-66)

- They stood looking at each other ; Mr.Gradgrind's face as white as the pursuer's..(hal 601, baris ke-98)

- 1 was brought up in that catechism when I was very young, sir, as you are aware.".(hal 602, baris ke-2)

- $\quad$...would not be as safe and good for me as my improved prospects in the Bank.".(hal 602, baris ke-14)

- "Bitzer," said Mr, Gradgrind, stretching out his hands as though he would have said, See how miserable I am!.(hal 602, baris ke-17)

- Mr. Sleary, who, with his mouth open and his rolling eye as immovably jammed in his head as his fixed one,.... (hal 602, baris ke-60)

- Mr. Gradgrind overwhelmed him with thanks, of course ; and hinted as delicately as he could,....(hal 603, baris ke-14)

- Mr. Sleary, stirring and drinking his brandy and water as he stood, went on:....(hal 603, baris ke-41)

- He went round to our children, one after another, as if he wath a theeking for a child he know'd....(hal 603, baris ke-85)

- "It theemth to prethent two thingth to a perthon, don't it, Thquire ?" said Mr. Sleary, musing as he looked down into the depths of his brandy and water:.... (hal 603, baris ke111)

- "Bite your nose off, ma'am •!" repeated Mr. Bounderby. "Tour nose! " meaning, as Mrs. Sparsit conceived....(hal 604, baris ke-43)

- Such an establishment as your relation, Lady Scadgers's, now.(hal 604, baris ke-104)

- ....that a long period has elapsed since I first habitually addressed it as the picture of a Noodle.(hal 604, baris ke-127)

- Did he catch, any glimpse of himself making a show of Bitzer to strangers, as the rising young man, so devoted to his master's great merits,....(hal 605, baris ke-23)

- Here was Louisa on the night of the same day, watching the fire as in days of yore, ....(hal 605, baris ke-70)

- ....,with such extenuation as his years and temptation ....(hal 605, baris ke-78)

- a woman working, ever working, but contentto do it, and preferring to do it as her natural lot,...(hal 605, baris ke-97)

- Herself again a wife-a mother-lovingly watchful of her children, ever careful that they should have a childhood of the mind no less than a childhood of the body, as knowing it to be even a more beautiful thing,....(hal 605, baris ke-116)

- she holding this coarse as part of no fantastic vow, or bond, or brotherhood, or sisterhood, or pledge, or covenant, or fancy dress or fancy fair; but, simply as a duty to be done,....(hal 606, baris ke-5) 


\subsection{Penggunaan Similes "like"}

- Mr. Bounderby, quite confounded, stood stock still in the street after his fatherin- law had left him, swelling like an Immense soap-bubble, without its beauty,... (hal 597, baris ke38)

- He raises his eyes to where she stood, like a good fairy in his house....(hal 598, baris ke7)

- In a preposterous coat, like a beadle's, with cuffs and flaps exaggerated to an unspeakable extent....(hal 600, baris ke-59)

- ....his hands, with the black partly worn away inside, looking like the hands of a monkey.(hal 600, baris ke-100)

- "1 don't want money mythelf, Thqirire; but Childerth ith a family man, and you watch to like to offer him a five-pound note, it mightn't be unacceptable.(hal603, baris ke-18)

- Now, Thquire, if your daughter will etheuthe me, I thouldlike one parting word with you."(hal 603, baris ke-37)

- "Thethilia my dear, kith me and good bye! Mith Thquire, to thee you treating of her like a thithter,....(hal 603, baris ke-125)

- ...over and over in his mind, until it accumulated with turning like a great snowball.(hal 604, baris ke-18)

- Thus saying, Mrs. Sparsit, with her Roman features like a medal struck to commemorate her scorn of Mr. Bounderby, ....(hal 605, baris ke-5)

\subsection{Penggunaan Metaphors}

Metaphors atau metafora dapat diartikan sebagai bentuk simile yang tersirat. Metafora tidak menyatakan satu hal itu sama seperti yang lain atau bertindak sebagai yang lain, sebaliknya menyatakan bahwa dua hal itu satu dan sama. Metafora adalah bentuk pernyataan yang tidak masuk akal, misalnya, "waktu adalah pencuri." Waktu sebenarnya tidak mencuri dari kita, tetapi lewat metafora tersebut terdapat gagasan bahwa jam atau hari terkadang tampak berlalu tanpa kita sadari (Alm-Arvius, 2003).

- The word was so sharp,....... (hal 602, baris ke-115)

- Mrs. Sparsit sat by the fire,......(hal 604, baris ke-33)

- Mrs. Sparsit gave him a look of the darkest scorn,......(hal 604, baris ke-89)

- Mr. Bounderby, very red and uncomfortable,.......(hal 604, baris ke-104)

- A woman of a pensive beauty,......(hal 605, baris ke-90)

\subsection{Pengaruh penggunaan similes dan metaphors pada tulisan berbentuk deskriptif}

Dari analisa diatas, ditemukan penanda yang membedakan antara gaya bahasa yang menggunakan similes dan metaphors, yaitu makna yang terkandung dari novel tersebut. Penanda gaya bahasa similedalam novel tersebutadalah penghubung bagaikan atau bagai (as) dan seperti (like). Sedangkan penanda gaya bahasa metafora yaitu analogi yang membandingkan dua hal secara langsung, atau satu hal yang dianggap sama.

Gaya bahasa simile dan metafora memiliki fungsi untuk menggerakkan imajinasi pembaca dalam memahami suatu karya sastra.Gaya bahasa similedalam novel berjudul hard time memiliki fungsi memperkuat dan mempertegas. Sedangkan fungsi gaya bahasa metafora, yaitu untuk meningkatkan efek dengan jalan memperkenalkan serta membandingkan suatu benda atau hal tertentu dengan benda atau hal lain yang lebih umum sehingga dapat menghidupkan cerita pada novel tersebut. Dengan menggunakan kedua jenis gaya bahasa ini dapat memberikan rincian atau detail tentang objek sehingga dapat memberi pengaruh pada emosi dan menciptakan imajinasi pembaca bagaikan melihat, mendengar, atau merasakan langsung apa yang disampaikan oleh penulis. 


\section{Kesimpulan}

Berdasarkan hasil dari penelitian diatas, dapat disimpulkan bahwa penggunaan similes pada novel tersebut lebih menekankan pada penggunaan "as" dibandingkan penggunaan "like". Penggunaan similes "as" dan "like" pada novel tersebut banyak digunakan sebagai bentuk dari figurative speech yang dibuat sebagai perbandingan antara dua objek dari berbagai jenis.

Sedangkan penggunaan metaphors hanya ditemukan beberapa bentuk saja, dikarenakan pada penulisan ini banyak menggunakan direct speech atau ungkapan langsung, sehingga sangat sulit untuk memasukkan unsur metafora kedalam cerita, selain itu bentuk pengungkapan berupa perbandingan satu hal dengan hal lain pada novel ini lebih menekankan pada penggunaan kata "as" dan "like" sehingga fungsi metafora sendiri tidak begitu dibutuhkan dalam novel ini.

\section{Saran}

Berdasarkan kesimpulan penelitian diatas, dapat diambil saran yaitu perlunya penelitian lebih lanjut pada karangan deskriptif, karena pada karangan deskriptif terdapat ciri-ciri lain yang dapat memperkuat makna cerita tersebut yaitu berupa penggunaan gaya bahasa hiperbola dan interesting verbs yang merupakan bagian dari karangan deskriptif untuk mendukung cerita atau tulisan tersebut menjadi suatu karangan yang dapat memberikan makna dan gambaran yang jelas kepada pembaca.

\section{Ucapan Terimakasih}

Ucapan terima kasih kami sampaikan kepada Institusi dan P3M Politeknik Negeri Balikpapan yang sudah memberikan dorongan baik secara moral maupun materil demi terlaksananya kegiatan penelitian ini sehingga kami dapat melaksanakan penelitian ini dengan lancar dan mencapai hasil yang maksimal. Kami berharap semoga kegiatan penelitian ini bisa membawa manfaat yang luas untuk peningkatan IPTEKS.

\section{Daftar Pustaka}

Alm-Arvius, Christina.(2003). Figures of Speech.Sweden: Studentlitteratur

Budiyono. (2003). metodologi penelitian. surakarta: uns press. 4

Deterding, (2001)David H., Poedjosoedarmo, Gloria R.The grammar of english. New Jersey: Prentice Hall

Gerot, Linda., Wignell, Peter. (2000). Making Sense Of Functional Grammar. Australia: Gerd Stabler Griffiths, Patrick. (2006). An Introduction To Figure Of Speech . Edinburgh University Press Ltd

Johnson, Burke And Christensen, Larry. (2000). Educational Research. Quantitative And Qualitative Approach. Santiago: A Pearson Education Company

Kosasih, Engkos. (2011). Ketatabahasaan Dan Kesusastraan Cermat Berbahasa Indonesia. Bandung: Yrama Widya

Malvini, Shawna, (2017). Metaphor analysis. The International Encyclopedia of Communication Research Methods: John Wiley \& Sons, Inc.

Semi, M. Atar.(1996). Menulis Efektif. Padang: Angkasa

Suzanne, Eggins. (2004). An Introduction To Systemic Functional Linguistics.2nd Ed.London: Continuum International Publishing Group

Sudarma, Momon. (2013). Mengembangkan Keterampilan Berpikir Kreatif. Jakarta: kharisma putra utama offset

Widjono, Hs. (2007). Bahasa Indonesia: Mata Kuliah Pengembangan Kepribadian di Perguruan Tinggi (Rev). Jakarta: Grasindo

Widyamarta. (1997). Kreatif Mengarang.Yogyakarta : Kanisius 